\title{
Characterization of urinary bladder in Khat chewing Yemeni students using Ultrasonography
}

\author{
Elsafi Ahmed Abdalla ${ }^{1}$, Caroline Edward Ayad ${ }^{1,}{ }^{*}$, Amin Mohsen Amer ${ }^{2}$, Amel AlGadal ${ }^{1}$ \\ ${ }^{1}$ Sudan University of Science and Technology, College of Medical Radiological Science, Khartoum, Sudan \\ ${ }^{2}$ Radiology Department, Yemen-Sana'a, Ultrasound Clinic, Sana, Yemen
}

\section{Email address:}

Dr.elsafi@gmail.com (E. A. Abdalla), carolineayad@yahoo.com (C. E. Ayad), carolineayad@sustech.edu (C. E. Ayad), Aminmohsin@yahoo.com (A. M. Amer),Amelgadal@yahoo.com(A. AlGadal)

\section{To cite this article:}

Elsafi Ahmed Abdalla, Caroline Edward Ayad, Amin Mohsen Amer, Amel AlGadal. Characterization of Urinary Bladder in Khat Chewing Yemeni Students Using Ultrasonography. International Journal of Medical Imaging. Vol. 2, No. 2, 2014, pp. 10-13. doi: 10.11648/j.ijmi.20140202.11

\begin{abstract}
Khat is a natural stimulant from the Catha Edulis plant and is cultivated in the Republic of Yemen and certain areas of East Africa. Khat produces a modest degree of euphoria and slight hypomania. It results in insomnia and appears to improve the users' alertness and concentration. The main objective of this study was to determine ultrasound findings of urinary bladder among Yemeni khat chewers higher education students. Fifty khat chewers volunteers from higher Education levels were selected as cases, and twenty non-khat chewer volunteers at University level serving as control group. All of them were undergone urinary bladder ultrasound scan. This study revealed that the high frequency of students who chewed khat were from Dhamar area. The study showed that there is a linear relationship between the urinary bladder wall thickness and chewing Khat for years and hours and the residual urine volume is greater in students who chewed the Khat than the control group. Correlation is significant at the $P=0.000$ for chewing Khat for years and hours.
\end{abstract}

Keywords: Khat, Ultrasound, Urinary Bladder

\section{Introduction}

Khat is a tree that grows in different parts of the world, extending from East to Southern Africa, Yemen and Madagascar. [1, 2]Chewing khat has a deep-rooted social and cultural tradition. [3] Khat is a central nervous stimulating drug [4].Unwanted effects associated with khat are sleeplessness, nervousness and weakness [4]. Gastro-intestinal tract problems are common, such as Anorexia and constipation [5,6]. Khat has been implicated in a number of other cardiovascular conditions[5,6,7]. There is also increased prevalence of respiratory problems [4].One of the obvious side effects of chewing khat leaves in males is temporary interference with micturition with hesitation and poor flow. The urinary bladder wall thickness is important sign that must be evaluated whenever scanning the urinary bladder.[8]The Ultrasound is informative method in diagnosing urinary bladder diseases [8]. The khat chewing habit in Yemen is deeply rooted in society, being a common daily activity [9] .However; khat has effects on urinary tract, so we need easy repeatable method of investigation to facilitate investigation of those effects. The main objective of this study is to determine ultrasound findings of urinary bladder such as wall thickness, pre and post voiding bladder volume, as well as intra luminal abnormal findings of urinary bladder among Khat Chewers Yemeni at higher education levels.

\section{Materials and Methods}

\subsection{Study Population, Area and Duration}

The inclusion criteria were healthy students in higher educational levels with different ages between (21-36) years, and different regions of Yemen including Albaia (4\%),Aldhaei(10\%),Amran(4\%),Dhamar(20\%),Labb(18\%), Lahj(6\%),Sadah(10\%),Sannaa(6\%),Soquatra(4\%), Taiz(18\%) .Fifty cases of them, were khat chewers and twenty were non-khat chewers serving as control group. The Excluded criteria were the cases found to be with diseases affecting the urinary bladder including Hypertension, Diabetes Mellitus, history of prostatic lesion, BPH, heavy smoking, history of Belharziasis, previous operation of urinary bladder or prostate and long standing medication. The study was conducted at 
Yemen-Sana'a, Ultrasound Clinic in Taiz Street, and was conducted during the period from February 2012 to May 2012 .

\subsection{Ultrasound Machine and Scanning Technique}

Ultrasound machine used was, "Fukuda" with a $3.5 \mathrm{MHz}$ convex transducer. Patients were examined in the supine position, and ultrasound coupling gel was applied. The patients bladders were scanned trans-abdominally, using an ultrasound probe on the abdomen at the Supra-Pubic Region, using transverse and sagittal views. The volumes of the bladders were taken pre and post micturition, using volume measurement equation which is set in ultrasound machine. The bladder was in the correct degree of bladder fullness since too little fluid may not provide the window necessary for adequate pelvic scanning. After the scans were performed, the patients were asked to partially void and the bladder was rescanned and films were taken after voiding. The character and sonographic appearance of the distended urinary bladder is smooth, thin, medium level echogenic walls and contain no echoes. To assess wall thickness; the bladder was reasonably distended. The longitudinal appearance of the normal urinary bladder consists of a triangular shaped structure with the anterior side parallel to the anterior abdominal wall; the posterior side parallels the rectum in the male. The superior side extends obliquely from the region superior to the prostate towards the umbilicus. In transverse scans, with a distended bladder, the lateral caudal margins are bordered by the acetabula which constrict its shape and make the bladder appear square. Above the acetabula the bladder has a more rounded shape. Scan Technique for obtaining Bladder Volume was $\mathrm{V}=(\mathrm{H} \times \mathrm{W} \times \mathrm{D}) \times 0.523$ the sagittal image provides the craniocaudal distance $(\mathrm{H})$ and the AP distance (D). The transverse image at its widest dimension provides the width (W).The data were collected and were analyzed using SPSS programme version 16

\section{Results}

The following tables and figures presents the data obtained from Khat- Chewers among Yemeni higher education students.

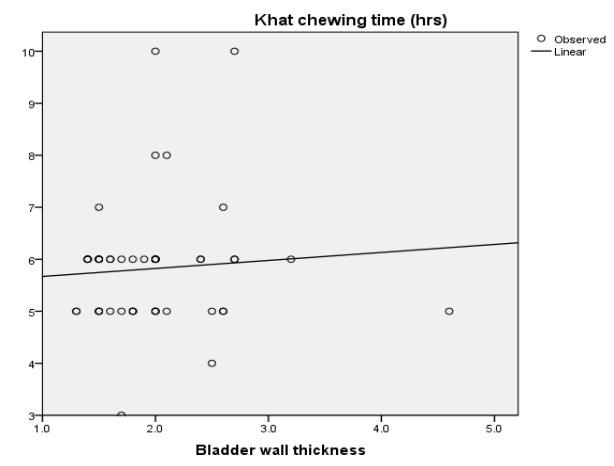

Figure 1. Shows the relation between khat chewing Time (hours.) and urinary bladder wall thickness( there is linear relation between the bladder wall thickness and increasing the period of chewing Khat).

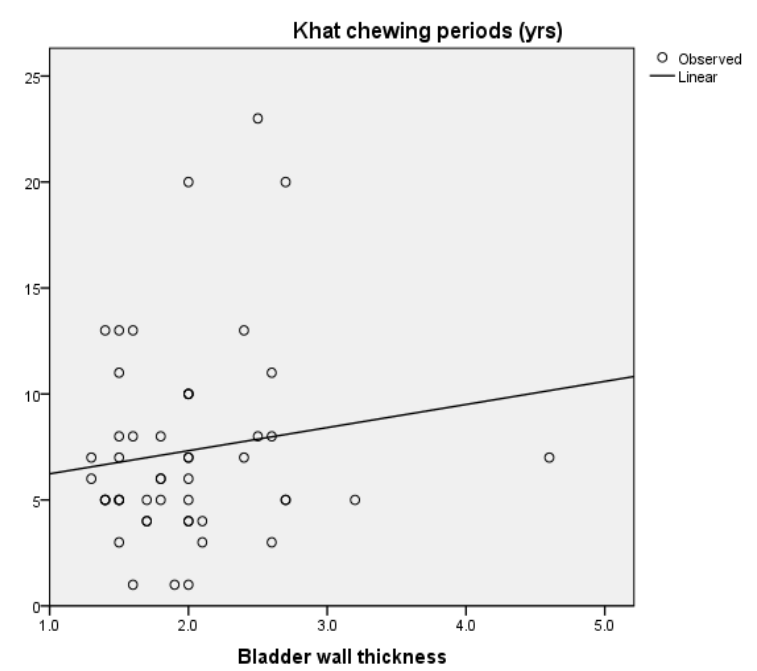

Figure 2. Shows the relation between khat chewing period (years)and urinary bladder wall thickness(there is linear relation between the bladder wall thickness and increasing the period of chewing Khat)

\section{Discussion}

Khat- chewing, is a major health problem in Yemen .The data in this research were collected from (50) volunteers Yemeni high educational students, who were khat -chewers serving as study group , and (20) volunteers ,Yemeni University students who never chewed khat serving as control. Table (1) Showed that the chewing period in years was found to be high for $1-5$ years $23(46 \%)$, then $6-10(18(36 \%))$, and 20years $(8(16 \%)$. The duration time of Khat chewing in hours, were found to be maximum at 6 hours (24 student out of 50(48\%)) as presented in table( 2 )

Table 1. Shows the distribution according to the Khat chewing period

\begin{tabular}{cc}
\hline Khat chewing periods (Yrs) & Frequency and Percentages\% \\
\hline $1-5$ & $23(46 \%)$ \\
$6-10$ & $18(36 \%)$ \\
$11-20$ & $8(16 \%)$ \\
Total & $50(100 \%)$ \\
\hline
\end{tabular}

Table 2. Shows the distribution according to the Khat chewing time (hrs.)

\begin{tabular}{cc}
\hline Khat chewing time (hours.) & Frequency And Percentages\% \\
\hline 3 & $1(2 \%)$ \\
4 & $1(2 \%)$ \\
5 & $18(36 \%)$ \\
6 & $24(48 \%)$ \\
7 & $2(4 \%)$ \\
8 & $2(4 \%)$ \\
10 & $2(4 \%)$ \\
\hline
\end{tabular}


Regarding the data presented in tables $(1,2)$ the study group was students whose ages were between $21-36$ years. The starting time of chewing khat was approximately at 8 years old or less. This reflects that the stimulating effects seem to have a strong influence on the social and cultural life of the Yemeni communities .In Yemen; fathers give school-aged children khat leaves to make them more energetic and stimulated, believing that khat chewing increases the ability to study better. Young adolescents have their own khat sessions as they start to form their own friendships.[9]

Table 3. shows the correlations between khat chewing periods (Yrs.) ,urinary bladder volume and urinary bladder wall thickness

\begin{tabular}{lccc}
\hline & \multicolumn{3}{c}{ Correlations } \\
\cline { 2 - 4 } & Age & periods (Yrs.) & Time (hrs.) \\
\hline Age & & $.000^{* *}$ & $.045^{*}$ \\
Periods /years & $.000^{* *}$ & & $.009 * *$ \\
Time /hours & $* .045$ & $* * .009$ & \\
Pre-voiding volume & .928 & .780 & .721 \\
Post voiding volume & $.000 * *$ & $.000^{* *}$ & $.000^{* *}$ \\
\hline
\end{tabular}

**Correlation is significant at the 0.01 level (2-tailed).

* Correlation is significant at the 0.05 level 2-tailed).

The urinary bladder volume, and wall thickness, were evaluated by ultrasound and was correlated with the usage of khat as chewing in hours and chewing in years. There was broad distribution in cases according to the post voiding residual urine volume with (mean: $7.9 \pm 6.30$ ) as compared with that of control (mean: $5.3 \pm 1.20$ ). These results agreed with the previous study [10] which stated that there was a variation in the distribution of post-void residual urine volume across age groups. the study showed that there is a significant relationship between the variables, and there was strong positive correlation between khat-chewing periods(Yrs.) and post voiding volume $\left(\mathrm{r}^{2}=0.586, \mathrm{P}<0.01\right)$ and there was strong positive correlation between khat chewing time(hrs.) and post voiding volume $(\mathrm{ml})\left(\mathrm{r}^{2}=0.615\right.$, $\mathrm{P}<0.01)$ table $(3)$.

Table (4) showed distribution of bladder wall thickness. It was found to be in the range 3.3(1.3-4.6) with (mean: 1.97 $\pm 0.58)$ as compared with that of control, with thickness range 1.3(1.4-2.7) (mean: $1.9 \pm 0.4$ ), that means it was thickened in the group with Khat-chewing activity. There was positive correlation between khat chewing in (Yrs.) and bladder thickness $\left(\mathrm{r}^{2}=0.183, \mathrm{P}<0.01\right)$ and correlation between khat chewing time in (hrs.) and the bladder wall thickness r2=.075.was also presented. Figures $(2,3)$, presented a linear relationship between the bladder wall thickness, and Khat- chewing time/hours and chewing period/years. The justification of these results is that Khat affected the relaxation of bladder wall, and closure of internal sphincter, as well as causing urine retention and reducing urine flow rate [11] this is consistent with the findings of the presence of residue urine detected in the chewer group. During khat chewing, Cathinone, Cathine and nor-ephedrine, are extracted into saliva, and the oral buccal mucosa plays a major role in absorption [12]. Cathinone induces release of Dopamine, Serotonin (5-hydroxytryptamine, 5-HT) and nor-adrenaline from pre-synaptic neuronal terminals, and has further been suggested to inhibit neurotransmitter reuptake [13]. Cathinone, Cathine and nor-ephedrine have been shown to act as substrates at the nor-adrenaline and dopamine transporters, to bind $\alpha 2$-adrenergic receptors [14, 15], and Cathinone has in addition been reported to bind 5 -HTreceptors $[15,16]$. The $\beta 1$-adrenergic receptor was suggested to mediate khat-induced increase in systolic blood pressure and pulse rate [17], whereas $\alpha 1$-adrenergic receptor has been implicated in bladder dysfunction following khat chewing [18].This what was detected in the sample. These results highlighted the impact of khat chewing in the life of Yemeni students.

Table 4. Shows The Mean, And Standard Deviation Of Variables In Study Group And Control Group

\begin{tabular}{lccc}
\hline & \multicolumn{2}{c}{ study group } & \multicolumn{1}{c}{ control group } \\
\cline { 2 - 4 } & Range(Min-Max) & Mean \pm STDV & Range(Min-Max) \\
\hline Age & $18(21-39)$ & $25.5 \pm 4.16$ & $29(23-52)$ \\
Khat chewing periods(Yrs.) & $22(1-23)$ & $7.30 \pm 4.63$ & - \\
Khat chewing time (hrs.) & $7(3-10)$ & $5.8 \pm 1.21$ & - \\
Pre-voiding volume (ml) & $251.4(34.5-285.9)$ & $133.9 \pm 62.3$ & $132.0(78-210)$ \\
Post voiding volume (ml) & $28.4(0.0-28.4)$ & $7.9 \pm 6.3$ & $119.6 \pm 34.4$ \\
Bladder wall thickness & $3.3(1.3-4.6)$ & $1.97 \pm .58$ & $5.5(3.0-7.5)$ \\
\hline
\end{tabular}

\section{Conclusion}

In conclusion, the study showed changes concerning the post voiding residual urine results, as well as urinary bladder wall thickness in the chewer group, which are considered as an indicator for the importance of awareness among the school -aged children in Yemen, regarding Khat chewing.
The study highlights the hazards of khat use. The researchers suggested that the reason of failure to protect the public from the usage of khat is that; the use of Khat is an established cultural tradition for many social situations in the areas of primary cultivation, as Yemen. The association of regular Khat- chewing with various health problems needs to be considered. Hence, strong measures need to be taken for 
establishing a greater awareness among the most common users as school students, college students, and general public Recommendations included the importance of increasing public awareness of the potential health hazards of Khat -chewing and introduction education about Khat into the Primary and Secondary Schools.

\section{Acknowledgements}

Our Thanks for Yemen-Sana'a, Ultrasound Clinic and Sudan University of Science and Technology - College of Medical Radiological Science.

\section{References}

[1] J. G. Kennedy,. The Flower of Paradise - The Institutionalized Use of the Drug Khat In North Yemen. D. Reidel: Dordrecht(1987)

[2] A. D. Krikorian, Kat and its use: an historical perspective. Journal of Ethno pharmacology (1984). 12, 115-178

[3] P. Kalix, O. Braenden,. Pharmacological aspects of the chewing of khat leaves. Pharmacological Reviews 37, (1985). 149-164.

[4] J. G ,Kennedy, J.Teague, W. Rokaw, E. Cooney,. A medical evaluation of the use of khat in North Yemen. Society Science and Medicine (1983). 17, 783-793

[5] H Halbach,. Medical aspects of the chewing of khat leaves. Bulletin of World Health Organization (1972). 47, 21-29.

[6] A. J Giannini, H. Burge, J. M Shaheen , W. A. Pnce, Khat: another drug of abuse? Journal of Psychoactive Drugs (1986). $18,155-158$.

[7] Y .Gendron, C.H .Ardouin, J. Martine. Accidents cardio vasculaires aigus declenches par le khat. Medicine Tropical (1977). 37, 69-72 .

[8] Mumtaz Ahmad. Role of Plain X-Ray KUB and Renal Ultrasound in evaluation Of Renal Colic. A.P.M.C Vol: 4 No.2 July-December 2010
[9] Ahmed Al-Motarreb, Kathryn Baker and Kenneth J Broadley Khat: pharmacological and Medical Aspects and its Social Use in Yemen Phytother. Res. 16, 403-413 (2002)

[10] A. D Krikorian, Khat and its use: an historical perspective. Journal of Ethnopharmacology (1984). 12, 115-178

[11] A.A.Nasher, A.A .Al-Qiribi, M.A Ghafoor, Murray-Lyon IM. Khat chewing and bladder neck dysfunction a randomized controlled trail of alpha -1- adrenergic blocked. Br J Urol 1995; 75:597-98.

[12] S.W .Toennes, S. Harder, M .Schramm, C. Niess, G.F. Kauert: Pharmaco kinetics of cathinone, cathine and norephedrine after the chewing of khatleaves. Br J Clin Pharmacol 2003, 56(1):125-130.

[13] P .Kalix: Pharmacological properties of the stimulant khat. Pharmacol Ther1990, 48(3):397-416.

[14] L. Cleary, J.R .Docherty: Actions of amphetamine derivatives and cathinoneat the noradrenaline transporter. Eur J Pharmacol 2003, 476(1-2):31-34

[15] R.B. Rothman, N Vu, J.S Partilla, B.L .Roth, S.J .Hufeisen, Compton-Toth B.A, J.Birkes, R .Young, R.A. Glennon: In vitro characterization of ephedrine-related stereo isomers at biogenic amine transporters and the receptor omereveals selective actions as norepinephrine transporter substrates.J Pharmacol Exp Ther 2003, 307(1):138-145

[16] R.A Glennon, S.M Liebowitz: Serotonin receptor affinity of cathinone andrelated analogues. J Med Chem 1982, 25(4):393-397

[17] N.A Hassan, A.A Gunaid, F.M. El-Khally, M.Y Al-Noami, I.M Murray-Lyon: Khat chewing and arterial blood pressure. A randomized controlled clinical trial of alpha-1 and selective beta-1 adrenoceptor blockade. Saudi Med J 2005, 26(4):537-541

[18] A.A Nasher, A.A Qirbi, M.A Ghafoor, A .Catterall, A. Thompson, J.W.A Ramsay, I.M. Murray-Lyon. Khat chewing and neck bladder dysfunction. A randomized controlled trial of al adrenergic blockade. Br J Urol 1995; 75: 597-598 